\title{
Inmigración, territorio y escuela: un triángulo no equilátero
}

\author{
Jordi Domingo Coll y Olga Bernad Cavero \\ Universidad de Lleida (España)
}

En Cataluña, desde finales del siglo XX, la inmigración internacional ha introducido un nuevo elemento en la diversidad que se refleja en el territorio, en la sociedad y en la escuela. Los procesos sociales relacionados con la inmigración se añaden al equilibrio fluctuante que estos elementos mantienen en el seno de una sociedad y de su proyecto político. La escuela se ha enfrentado a nuevas demandas sociales y educativas para las que ha tenido que idear nuevas respuestas formativas en consonancia a los nuevos componentes sociales. Los datos estadísticos del Instituto Nacional de Estadística (INE), del Institut d'Estadística de Catalunya (IDESCAT), del Ministerio de Educación y de la Consellería de Educación del Gobierno Autónomo, evidencian una realidad a la que la inmigración suma un componente de diversidad cultural y religiosa. El artículo analiza los datos disponibles hasta el año 2018, haciendo un especial énfasis en el alumnado extranjero matriculado en los centros escolares de educación infantil y primaria de Cataluña, teniendo en cuenta la etapa educativa, la titularidad del centro, el país de origen y el territorio. La relación desigual entre inmigración, territorio y escuela afecta las estrategias de adaptación de los procesos educativos y muestra los retos que hay que afrontar.

Palabras clave: Inmigración, territorio, diversidad cultural, sistema escolar.

Immigration, territory and school: a non-equilateral triangle. In Catalonia, since the end of the 20th century, international immigration has introduced a new element of diversity in the territory, society and school. Social processes of segregation related to immigration are added to the fluctuating balance that these elements maintain within a society and its political project. The school has faced new social and educational demands for which it has had to devise new training responses in line with the new social components. The statistical data of the INE, IDESCAT, the Ministry of Education and the Ministry of Education of the Autonomous Government, show a reality to which immigration adds a component of cultural and religious diversity. This article analyzes the data available until 2018, making a special emphasis on foreign students enrolled in the schools of primary education of Catalonia, taking into account the educational stage, the ownership of the center, the country of origin and the territory. The unequal relationship between immigration, territory and school affects strategies for adapting educational processes and shows the challenges that must be faced.

Keywords: Immigration, territory, cultural diversity, school system.

Correspondencia Jordi Domingo Coll. Avenida Estudi General 4. C.P.: 25001 Lleida (España). E-mail: jdomingo@ geosoc.udl.cat. 
La investigación, que ha dado lugar a los resultados que se presentan a continuación, ha estado impulsada por una ayuda del programa Recercaixa, concretamente en el proyecto "Diversidad cultural e igualdad de oportunidades en la escuela" (Convocatoria Recercaixa, 2015).

Los efectos de los flujos migratorios van más allá de unos simples datos estadísticos y se dejan sentir, con intensidades diferentes, en las sociedades de acogida. Cataluña es una comunidad con tradición en movimientos migratorios pero la experiencia de las últimas décadas ha supuesto un proceso diferente, con un flujo de gran intensidad y una diversidad inusitada hasta el momento (Domingo, 2016). Además del número de efectivos destacan la diversidad de orígenes, la distribución desigual en un territorio con tradiciones económicas diferentes, y unos efectos en la estructura de edades con efectos en todo el territorio, especialmente en el entorno escolar. La inserción de culturas exógenas en las estructuras económicas y culturales autóctonas ha creado una nueva realidad escolar (Bernad, 2016; Bernad y Llevot, 2018; Garreta, 2003; Llevot, Bernad, y Benabarre, 2018). Inmigración, territorio y escuela se convierten en los tres lados de un triángulo de estructura desigual, donde cada eje tiene un peso y un proceso que se adapta a realidades territoriales diferentes.

Si bien la inmigración es un elemento constante en el panorama social y territorial español, desde finales del siglo pasado, con la internacionalización y la diversificación de orígenes, se ha convertido en un tema de análisis para hacer frente a uno de los retos principales que se impone a la sociedad actual. Entre muchos otros, los trabajos de Cabré (1990), Giner (1997), Samper (2002), Cabré et al. (2007), Domingo (2007), Essomba (2014), Silvestre (2009) o Garreta (2016), dan muestras del efecto de este fenómeno sobre la sociedad y la producción académica. Siguiendo estos trabajos, se analizan los efectos de un proceso rápido en el tiempo, desigual en el espacio y en la sociedad que lo ocupa. Después del primer impulso de un proceso migratorio que, con más de dos décadas de protagonismo, ya ha alcanzado un grado de madurez y ha dado tiempo a la capacidad de reacción social, económica y política, aparece un paisaje con una marcada dualidad que impregna la sociedad catalana. Pinyol (2016) evidencia una dualidad social en relación con la inmigración que se suma a la dualidad campo-ciudad, agudizada desde los años cincuenta y sesenta del siglo XX. Una Catalunya joven, urbana, con amplias esferas de influencia, se sitúa frente a una Catalunya rural, envejecida y con poca capacidad para acoger nuevos habitantes, tal como se puede observar en los análisis hechos por autores como Roquer y Blay (2008), Bayona y Gil (2008) o Domingo y Bernad (2017). Esta situación resulta de un proceso de especialización económica que, durante el siglo XX, ha configurado una diversidad de espacios con dinámicas diferenciadas, tal como se puede seguir en Aldomà (2015). Los procesos rurales han ido quedando acotados en determinadas áreas cada vez más influenciadas por dinámicas urbanas más o menos lejanas. La transformación de la 
economía y sus procesos territoriales han creado respuestas sociales a las que la inmigración ha aportado su presencia: mientras se confirma la tendencia a la urbanización del territorio en ciudades pequeñas y medianas, se mantiene una Catalunya rural donde la aportación migratoria retrasa el envejecimiento y contribuye a mantener determinadas estructuras, entre las que se cuentan las educativas que inciden en la integración social.

Por otro lado, si bien la inmigración es una realidad que ha alterado significativamente la sociedad de acogida, se ha dejado sentir con una gran incidencia en el ámbito educativo. El sistema escolar se convierte en un punto de confluencia y encara los cambios que se producen en la sociedad. Y aunque la diversidad cultural no es un fenómeno nuevo en las escuelas, la aparición de nuevas culturas en la sociedad ha generado la necesidad de un cambio en la manera de considerarlas y de gestionarlas enel proceso educativo (Llevot, Molet, Garreta, Bernad, y Domingo, 2017; Bernad y Llevot, 2018; Llevot, Bernad, y Garreta, 2019) y de abordarlas en la formación inicial de los futuros docentes (Bernad y Llevot, 2016). La irrupción de la inmigración ha supuesto el paso de modelos que postulaban que la integración en una sociedad se debe experimentar desde la asimilación -por el grupo dominante- de los culturalmente diferentes, hasta discursos más actuales de reconocimiento y valoración de las «otras culturas» y religiones como se recoge, entre otros, en Portera (2008), en Llevot y Bernad (2015) y en Llevot et al. (2019). En el caso del Estado español, la evolución constatada en otras sociedades tampoco nos es ajena, aunque el ritmo y el momento no coincidan.

El Colectivo IOE (1996) destacaba la idea asimiladora de la educación española mientras que Palaudarias (1998) exponía intervenciones discursivas, normativas y compensatorias de las desigualdades como respuesta a una realidad que se iba imponiendo en aquellos años. La evolución muestra la imposición de una tendencia asimiladora y compensatoria que desplaza la educación intercultural dejándola en poco más que una utopía que se desarrollará según la realidad de cada centro escolar, según se observaba en Garreta (2011).

En consonancia con estos trabajos precedentes, las páginas que siguen analizan la relación desigual entre el actual proceso migratorio, el territorio catalán, con sus diferencias, y la escuela como elemento afectado por la realidad social.

\section{MÉTODO}

\section{Participantes}

El sujeto de estudio es la población extranjera residente en Catalunya, de la que se analiza la procedencia, y el segmento de población en edad escolar. 


\section{Instrumentos}

Se ha consultado datos del padrón municipal de habitantes ofrecidos por el Instituto Nacional de Estadística (INE), que se han complementado con los datos ofrecidos por el Institutd'Estadística de Catalunya (IDESCAT) que los ofrece desglosados por ámbito comarcal.

También se ha utilizado los datos del Ministerio de Educación, Cultura y Deporte y de la Consellería d'Educació de la Generalitat de Catalunya para las etapas del Segundo Ciclo de Educación infantil y Educación Primaria. Los datos ofrecen información en relación al tipo de centro y curso, origen de los alumnos, agrupación comarcal, provincial y del conjunto de Catalunya.

Para todos los datos se ha utilizado la serie temporal desde los años finales del siglo pasado hasta la actualidad. La información de base estadística se ha completado con la consulta bibliográfica y de los informes y entrevistas realizadas desde el Observatorio Socioeducativo y del Grupo de investigación Análisis Social y Educativa (GRASE), de la Universidad de Lleida (UdL), principalmente el proyecto "Diversidad cultural e igualdad de oportunidades en la escuela" (Convocatoria Recercaixa, 2015).

\section{Procedimiento}

Se han analizado los datos referidos al origen de la población, edad y residencia en el ámbito provincial, comarcal o de Catalunya como conjunto, así como del tamaño del municipio de residencia. El mismo proceso se ha realizado con los datos del ámbito educativo en relación al tipo de centro, origen de los alumnos, agrupación comarcal, provincial y del conjunto de Catalunya. Para su análisis y exposición se ha realizado un tratamiento con Excel, y se han creado gráficos, cuadros y mapas, estos últimos a través del Servicio de Cartografía Científica y SIG de la UdL.

\section{Análisis de datos}

Se ha analizado los datos referidos al origen de la población, edad y residencia en el ámbito provincial, comarcal o de Catalunya como conjunto, así como del tamaño del municipio de residencia. El mismo proceso se ha realizado con los datos del ámbito educativo en relación al tipo de centro, origen de los alumnos, agrupación comarcal, provincial y del conjunto de Catalunya. Para su análisis y exposición se ha realizado un tratamiento con Excel, y se han creado gráficos, cuadros y mapas, estos últimos a través del Servicio de Cartografía Científica y SIG de la UdL. 


\section{RESULTADOS}

\section{Inmigración y territorio}

La evolución de las cifras de inmigración muestra como las provincias catalanas han presentado porcentajes superiores a las de la media española. Con un proceso evolutivo similar, se inician a mediados de los años 90 del siglo pasado para llegar a su máximo en 2010, año a partir del cual se inicia un leve retroceso con lo que parece ser un ligero repunte en 2018. A lo largo de este proceso, y en ocasiones en paralelo a él, la sociedad catalana ha experimentado cambios que han afectado al territorio, a la cultura y a la educación, entre otros muchos aspectos de la vida cotidiana. Y si bien el mercado laboral parece haber sido el motor del proceso migratorio, la llegada de nuevos conciudadanos ha generado nuevas oportunidades, nuevas realidades que superan con creces el marco laboral.

Por otra parte, cabe tener en cuenta que la realidad migratoria ha afectado con intensidad desigual cada provincia pero, con excepción de la de Barcelona, el proceso ha sido prácticamente el mismo, como se verá más adelante.

Gráfico1. Catalunya: evolución de la inmigración (\%)

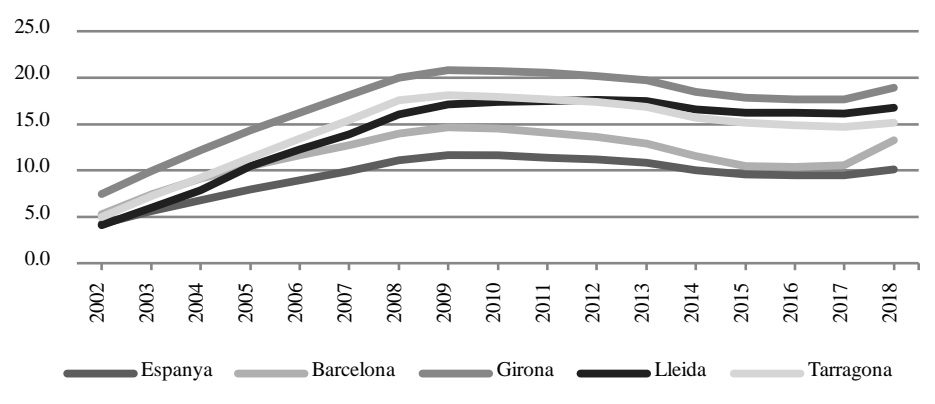

Fuente: INE. Elaboración propia.

En enero de 2018, en Cataluña, el $14.2 \%$ de la población era de origen extranjero. Superaba la media española $(10.1 \%)$ y se había convertido en el principal destino de la inmigración, concentrando el 22.9\%de España. Atrás quedaban los años del inicio del proceso de la internacionalización de la inmigración, los años de una euforia económica que impulsaba este fenómeno y, más tarde, los años de la crisis, con un lento cambio de tendencia y de relocalización de la población. Y aunque las ciudades fueron los núcleos donde se concentraron en mayor número, las principales zonas agrícolas del país también ofrecieron ocupación y oportunidades y vieron alterada su realidad cotidiana. 


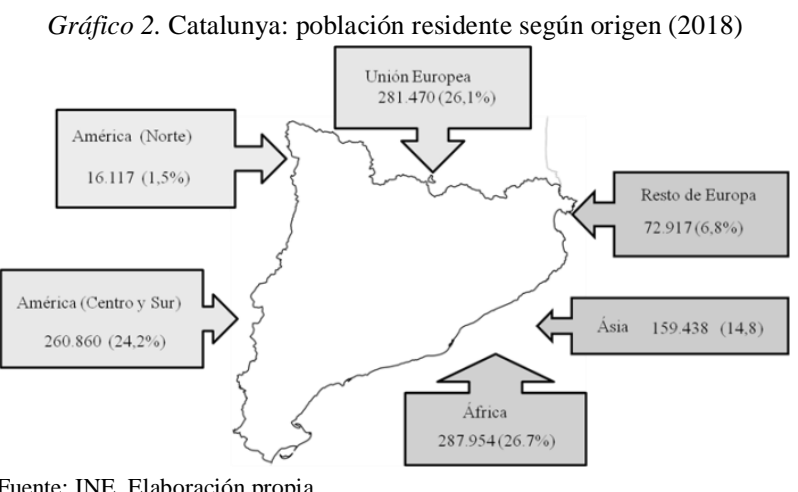

La diversidad de orígenes, reflejada en el gráfico anterior, aporta diversidad cultural en las calles, el lugar de trabajo y, principalmente, en la escuela. Destacan dos elementos:

-La población de origen marroquí se erige en el colectivo más numeroso y representa una de cada cinco personas inmigradas. Le siguen a mucha distancia la población rumana, con el $8.2 \%$ del total de extranjeros, la de origen chino, italiano y la de Paquistán. La diversidad, el número de efectivos y su herencia cultural son elementos a tener en cuenta en los procesos de integración y participación en una sociedad multicultural.

-La distribución territorial desigual. La gran ciudad y el territorio más urbanizado atrae el mayor porcentaje de inmigrantes. El tercer gráfico muestra como la provincia de Barcelona acoge a casi un $70 \%$ del total mientras que Girona y Tarragona se hallan entre el 13 y el $11 \%$. La provincia de Lleida, más alejada de los principales focos de la economía catalana queda con un $6.7 \%$ del total. Esto no implica que sean las provincias de Girona y Lleida donde la presencia de inmigrantes sea más significativa entre su población.

Por lo que respecta a la distribución comarcal, la Segarra i el Baix Empordà ven como uno de cada cuatro habitantes es de origen extranjero, mientras que en 13 comarcas más, representan entre un 15 y un $20 \%$ de población. Al otro extremo se encuentran comarcas que tienen entre un 7 y un $10 \%$ de población extranjera y que presentan un elemento común: tienen una economía industrial, como el Baix Llobregat (9.2\% de inmigración) o la han tenido y les afectó la crisis del sector, como el Berguedá $(6.9 \%)$ o el Ripollés (8\%). Mientras, comarcas de economía agrícola con poca población en relación al conjunto del país, mantienen unas tasas superiores al 10\%, como, por ejemplo, la Terra Alta (11.3\%) o el Priorat (11.1\%). 
Gráfico 3. Catalunya: distribución de extranjeros y su porcentaje sobre la población (2018)

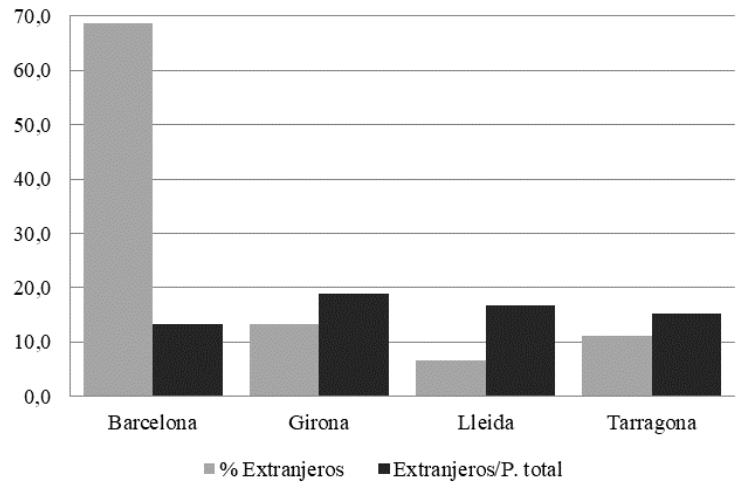

Fuente: INE. Elaboración propia.

El acceso al mercado de trabajo y al de la vivienda es un factor clave en la distribución de la población. En la distribución de la población autóctona pueden pesar otros elementos como la propiedad de la tierra, la herencia o un sentimiento localista. Pero entre la población inmigrada, en busca de una oportunidad para conseguir un futuro y sin raíces locales, se impone un sentido pragmático. Y esta parece ser la razón por la cual, a pesar de un dominio claro de la gran ciudad como polo de atracción, destacan los municipios de entre 5 y 20 mil habitantes por el porcentaje de población inmigrante que acogen. En el mismo sentido, cabe destacar los porcentajes de población inmigrada, alrededor del $10 \%$, en municipios de menos de mil habitantes, con la excepción de la provincia de Barcelona, donde ejercen un papel de renovación con el aporte de generaciones más jóvenes. También cabe destacar que la distribución de la población sigue una evolución, con un peso de los procesos históricos que afectan la economía y el asentamiento de la población. Es por esta razón, por ejemplo, que no existen municipios de entre cincuenta y cien mil habitantes en las provincias de Girona, Lleida y Tarragona, por ejemplo, y que algunos municipios que podrán considerarse "ciudades pequeñas" presenten unas tasas de inmigración superiores al 20\%, realmente significativas.

Tabla 1. Cataluña: porcentaje de población extranjera según el tamaño del municipio

\begin{tabular}{|c|c|c|c|c|c|c|c|c|c|c|}
\hline & $\begin{array}{c}\text { Menos } \\
\text { de } 101 \\
\text { hab. }\end{array}$ & $\begin{array}{c}\text { De } \\
101 \text { a } \\
500 \\
\text { hab. }\end{array}$ & $\begin{array}{c}\text { De } 501 \\
\text { a } 1.000 \\
\text { hab. }\end{array}$ & $\begin{array}{c}\text { De } \\
1.001 \mathrm{a} \\
2.000 \\
\text { hab. }\end{array}$ & $\begin{array}{c}\text { De } \\
2.001 \mathrm{a} \\
5.000 \\
\text { hab. } \\
\end{array}$ & $\begin{array}{c}\text { De } 5.001 \\
\text { a } 10.000 \\
\text { hab. }\end{array}$ & $\begin{array}{c}\text { De } \\
10.001 \mathrm{a} \\
20.000 \\
\text { hab. }\end{array}$ & $\begin{array}{c}\text { De } \\
20.001 \mathrm{a} \\
50.000 \\
\text { hab. }\end{array}$ & $\begin{array}{c}\text { De } 50.001 \\
\text { a } 100.000 \\
\text { hab. }\end{array}$ & $\begin{array}{c}\text { Más de } \\
100.000 \\
\text { hab. }\end{array}$ \\
\hline CATALUÑA & 4.1 & 7.1 & 9.8 & 9.5 & 9.7 & 10.6 & 12.5 & 15 & 11.6 & 16.9 \\
\hline Barcelona & 2.3 & 3.7 & 4.7 & 5.6 & 6.5 & 6.3 & 8.2 & 11.4 & 11.6 & 16.8 \\
\hline Girona & 9.1 & 9.2 & 10.6 & 10.2 & 10.3 & 14.8 & 22.9 & 24.8 & & 18.9 \\
\hline Lleida & 2.6 & 6 & 11.8 & 11.8 & 16.2 & 20.7 & 20.5 & & & 18.1 \\
\hline Tarragona & 5.6 & 8.7 & 10.6 & 9.8 & 11.1 & 15.6 & 15.9 & 17.8 & & 15.6 \\
\hline
\end{tabular}

Fuente: INE. Elaboración propia. 
Por lo que respecta a su distribución territorial, el siguiente mapa muestra el porcentaje de población inmigrante en cada comarca donde la Segarra i el Alt Empordà presentan una proporción superior al $20 \%$ de la población. Las funciones turísticas y la agricultura intensiva y pequeña industria refuerzan la concentración de población inmigrante en relación a la población autóctona mientras que áreas rurales o que han vivido severos procesos de desindustrialización quedan con los porcentajes menos significativos. La imagen muestra un territorio con contrastes donde la inmigración ha pasado a ser un elemento más en la composición demográfica ayudando a corregir, en algunos casos, los desequilibrios generados por dinámicas de urbanización incompletas.

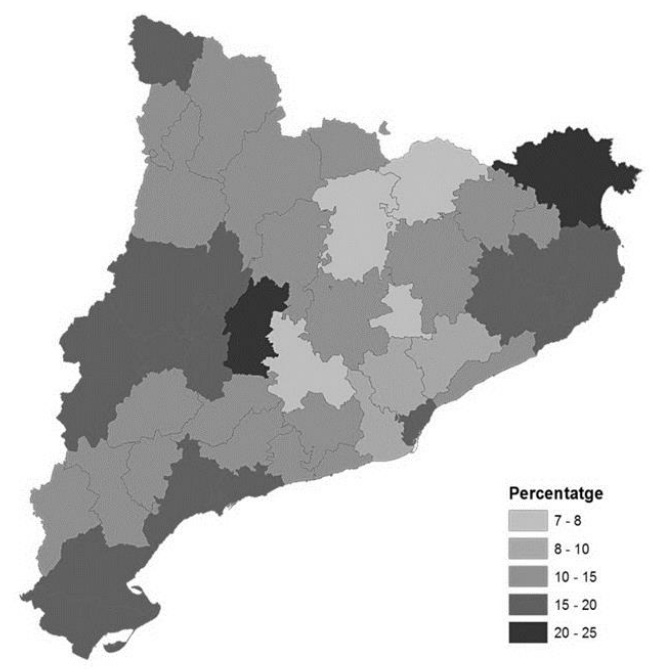

Figura 1. Cataluña: Población inmigrante por comarca (2017) Fuente: IDESCAT. Elaboración. SCC i SIG. UdL.

Un último elemento referente a la inmigración es la composición por edades. La llegada de nuevos efectivos demográficos altera las previsiones existentes en aspectos básicos del funcionamiento social. Así, por ejemplo, las previsiones sobre infraestructuras de sanidad o escuelas pueden verse alteradas puesto que la persona que emigra, generalmente, lo hace en edad productiva y, muchas veces, con una realidad familiar que la sigue. Y mientras los puestos de trabajo actúan de imán, los elementos que pueden considerarse sociales se crean cuando la necesidad apremia. Y las plazas escolares suponen uno de estos elementos, puede que uno de los más significativos, por ser la educación un punto de encuentro social, cultural y de trazado de futuro para las generaciones que lo viven. 
Gráfico 4. Catalunya: distribución de extranjeros y su porcentaje sobre la población

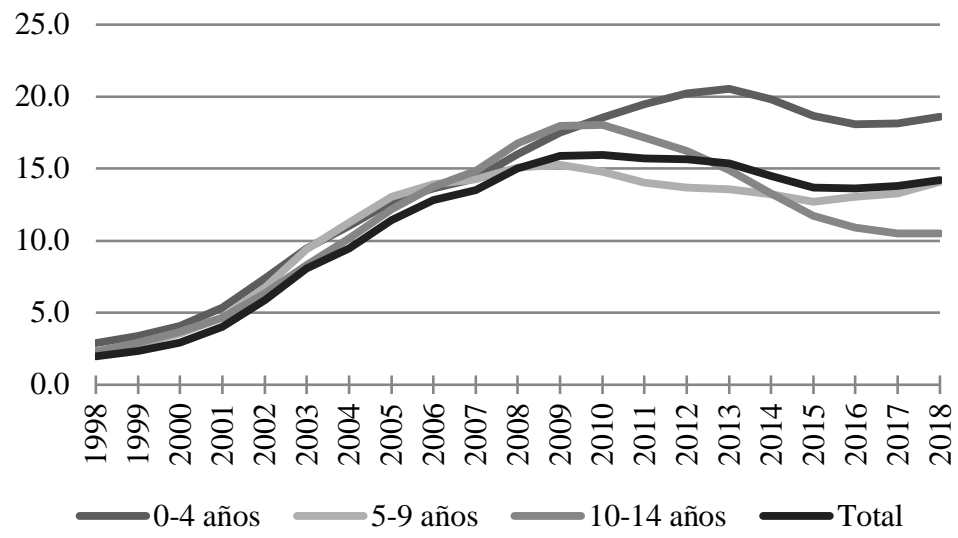

Fuente: INE. Elaboración propia

El gráfico precedente muestra la evolución del porcentaje de población extranjera, total y en relación con su misma franja de edad. Destaca el grupo de 0 a 4 años que llega a superar el $20 \%$ del total en unos años en los que la crisis económica afectaba más duramente la sociedad catalana. El porcentaje en esta franja de edad se mantiene significativamente por encima del resto e indica que en la escuela primaria la aportación demográfica se sitúa alrededor del $20 \%$ mientras que los dos grupos de edad que formarían parte de la escuela de Primaria se encuentran entre el 10 y $15 \%$. La evolución, que sigue a grandes rasgos la pauta marcada por el porcentaje de inmigración, indica una presencia considerable de la inmigración en el sistema escolar. Un sistema que ha experimentado cambios significativos en los últimos años para hacer frente a una realidad para la cual no estaba preparado.

\section{Inmigración y escuela}

La sociedad se ha ido adaptando a una realidad que a principios de los años 90 del siglo XX pocos esperaban. Desde entonces algunos barrios de las ciudades, desde las pequeñas de poco más de diez mil habitantes a las mayores, con Barcelona a la cabeza, se han convertido en espacios de inmigración. Algunos de estos espacios urbanos han vivido procesos de substitución de un colectivo, inmigrado a mediados de siglo XX desde algunas regiones españolas -en especial Andalucía y Extremadura-, por otro, con el origen como principal característica, otra vez. Esta realidad, que en ocasiones convierte algunos de estos barrios en lo que se podría llamar "guetos modernos", afecta al sistema escolar, cuando algunas escuelas se convierten en centros con un alto porcentaje de alumnos de origen inmigrante cuando no lo es el conjunto de la escuela. 
Algunas de las características del proceso de inmigración, así como de la diversidad en el colectivo, han obligado a repensar el entorno escolar, adaptándolo a una situación para la que no estaba preparado. Y este replanteamiento de posiciones se ha realizado a tres bandas, como mínimo, y no siempre a partir de un proceso de entendimiento. Así, mientras la administración intentaba satisfacer las necesidades más apremiantes, algunos centros escolares públicos se enfrentaban a un día a día para el que no tenían recursos y algunos centros concertados se convertían en "refugio" de familias autóctonas. Por otro lado, algunas familias "huían" de algunos centros que se estaban convirtiendo en verdaderos centros de acogida escolar mientras que otras familias inmigradas con un mínimo de posibles optaban por escolarizar a sus hijos en escuelas concertadas para obtener un cierto "prestigio social".

El gráfico 5 muestra la evolución del porcentaje de alumnos matriculados en la escuela pública y privada en Catalunya. Resulta sencillo de observar que la escuela pública se ha ocupado de atender la mayor parte, la casi totalidad, del alumnado mientras que la escuela privada ha ido incrementando tímida y lentamente su participación. Cabe tener en cuenta que, en base al curso 1997-1998, la población estudiantil de origen extranjero en el segundo ciclo de Educación Infantil se multiplica por 8.3 mientras que el global del alumnado sólo se multiplica por 1.6 en estos veinte años. Un poco menor (6.1) es el resultado entre los alumnos en Educación Primaria mientras que el global es de 1.5. Por esta razón, la diferencia entre los dos tipos de escuela ha favorecido la creación de verdaderos "centros gueto", con la mayoría de sus alumnos de origen inmigrante, mientras que en otros centros de la localidad, de titularidad privada, su presencia era casi anecdótica. Esta realidad se ha ido creando desde el inicio de la ola de inmigración y ha ido repitiendo una imagen negativa de la nueva población que afecta, también, al ámbito escolar. Esta imagen negativa ya se había producido a lo largo de los años 50 y 60 del siglo XX con la llegada de inmigrantes del resto de España y, hoy en día, sólo ha cambiado la "víctima".

Gráfico 5. Catalunya: alumnos extranjeros (\%)

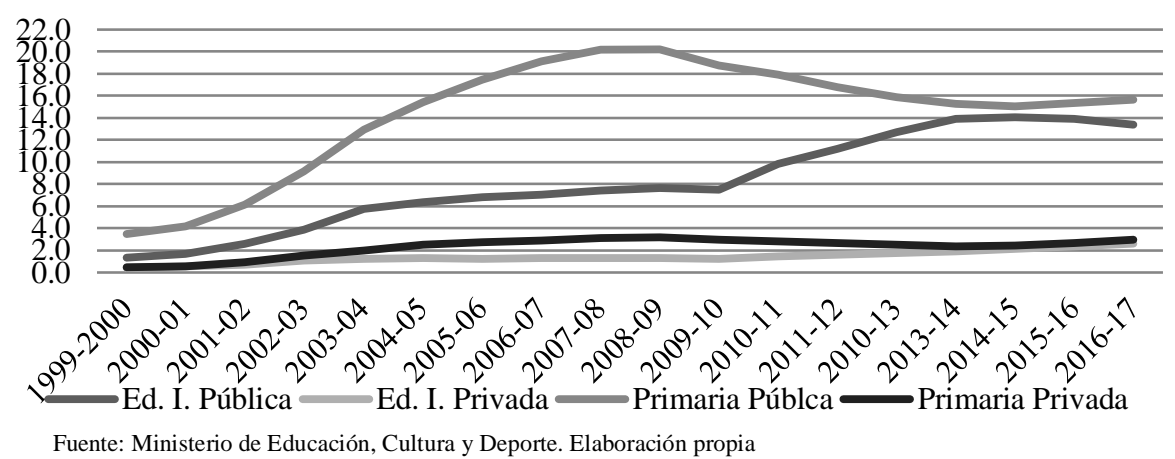


En este proceso destaca un cierto paralelismo con la evolución de la llegada de inmigrantes que se ve reflejada, básicamente, en la evolución del alumnado extranjero en centros públicos de Educación Primaria. El rápido ascenso desde principios de siglo hasta el estallido de la crisis en 2008 obligó a un planteamiento escolar de emergencia, con aulas "de acogida", específicas para atender la diversidad de situaciones con la que llegaban los alumnos en cualquier momento del curso. La inserción en el proceso de escolarización no resultaba sencillo cuando, de entrada, la lengua ya no era la misma y los niveles y tradiciones educativas era muy diferentes según los orígenes geográficos de los alumnos. Algunos directores de escuela comentaban que en aquellos momentos uno no podía saber cuántos alumnos tendrían nuevos cada día y que no disponían de recursos ni de la preparación necesaria como profesionales para hacer frente a una situación que resultaba desbordante.

La evolución muestra, también, como con la crisis económica se vive un aumento de la escolarización en el segundo ciclo de Educación Infantil. Si bien ya había una tendencia creciente a la escolarización a tan temprana edad, a partir de 2010, con los peores efectos de la crisis sobre la población y de manera más concreta, con la población inmigrante, que la escolarización infantil experimenta un crecimiento que casi dobla su porcentaje y, a partir de este año se queda en una tasa de alrededor del $14 \%$.

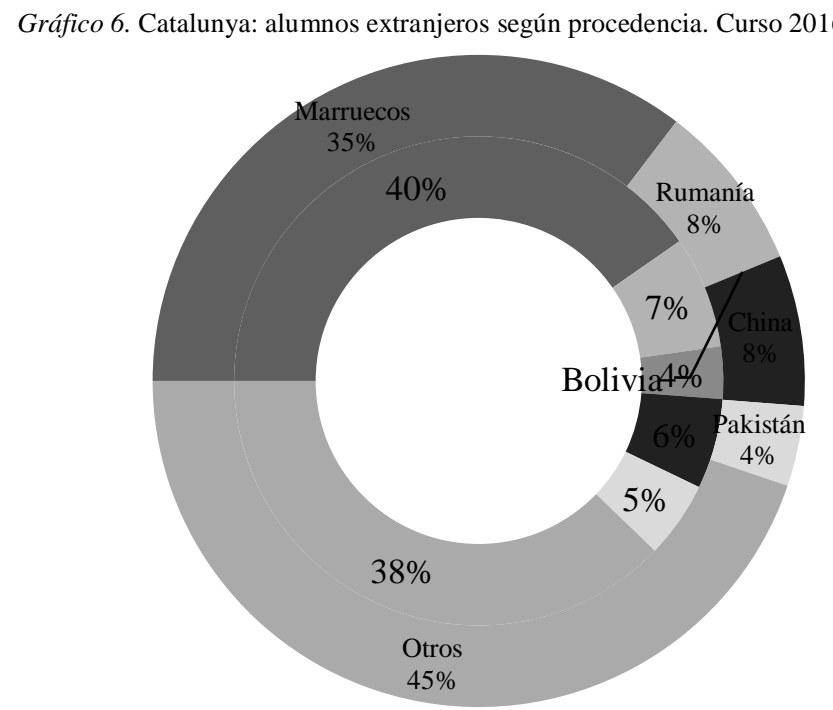

Fuente: Departament d'Ensenyament. Generalitat de Catalunya. Elaboración propia. 
Otro gran efecto de la inmigración es su composición que, en base al origen, permite hablar de la escuela como un espacio de encuentro multicultural. Destaca la gran presencia de alumnos de nacionalidad marroquí, muy alejada de los grupos que le siguen en importancia pero que forman un conjunto de muchas realidad es que abocan a la institución a un debate sobre que enseñar y como hacerlo. La escuela, pública o privada, ha tenido que hacer frente a esta diversidad aprendiendo a tratar y a integrar otros procesos culturales que le eran extraños pero que se han convertido en su cotidianidad. Y este proceso, realizado con la urgencia del momento, únicamente ha contado con la aportación de una experiencia de acierto-error, donde los alumnos, profesores, familias y administración han participado, con intensidad desigual, para enfrontar una realidad inesperada.

También cabe destacar que el sistema educativo español, marco de referencia normativo del sistema catalán, permite la existencia de centros que siguen el sistema educativo de países extranjeros. El gráfico 7 pone en evidencia la existencia de lo que se puede llamar "otro" tipo de inmigración que, localizada principalmente en el área de alrededor de Barcelona, genera otro tipo de impacto. Los veinte centros y sus casi 12.500 alumnos ponen en evidencia esta diversidad del proceso migratorio.

Gráfica 7. Sistemas educativos extranjeros en Catalunya. (2016-17)

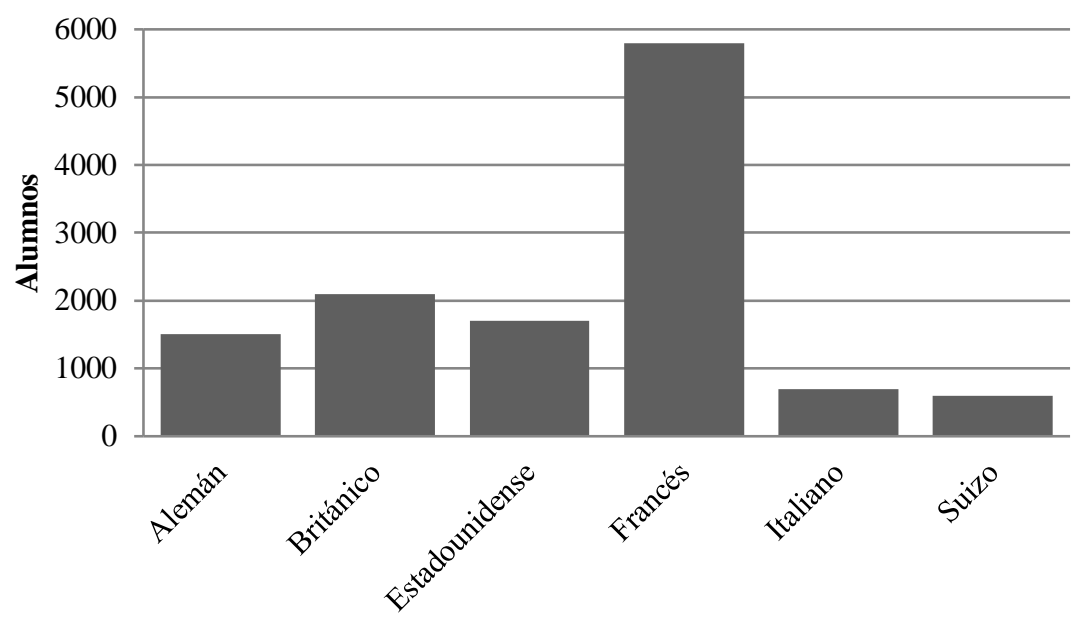

Fuente: Departament d'Ensenyament. Generalitat de Catalunya. Elaboración propia. 
Figura 2. Cataluña: principal colectivo inmigrante escolarizado en cada comarca (curso 2016-17)

\begin{tabular}{|l|l|l|}
\cline { 2 - 3 } \multicolumn{1}{c|}{} & Infantil & Primária \\
\hline ALT CAMP & & \\
\hline ALT EMPORDA & & \\
\hline ALT PENEDES & & \\
\hline ALT URGELL & & \\
\hline ALTA RIBAGORÇA & & \\
\hline ANOIA & & \\
\hline BAGES & & \\
\hline BAIX CAMP & & \\
\hline BAIX EBRE & & \\
\hline BAIX EMPORDA & & \\
\hline BAIX LLOBREGAT & & \\
\hline BAIX PENEDES & & \\
\hline BARCELONES & & \\
\hline BERGUEDA & & \\
\hline CERDANYA & & \\
\hline C. BARBERA & & \\
\hline GARRAF & & \\
\hline GARRIGUES & & \\
\hline GARROTXA & & \\
\hline GIRONES & & \\
\hline MARESME & & \\
\hline
\end{tabular}

\begin{tabular}{|l|l|l|}
\cline { 3 - 3 } \multicolumn{1}{c|}{} & Infantil & Primaria \\
\hline MOIANES & & \\
\hline MONTSIA & & \\
\hline NOGUERA & & \\
\hline OSONA & & \\
\hline P. JUSSA & & \\
\hline P. SOBIRA & & \\
\hline PLA DE L'ESTANY & & \\
\hline PLA D'URGELL & & \\
\hline PRIORAT & & \\
\hline RIBERA D'EBRE & & \\
\hline RIPOLLES & & \\
\hline SEGARRA & & \\
\hline SEGRIA & & \\
\hline SELVA & & \\
\hline SOLSONES & & \\
\hline TARRAGONES & & \\
\hline TERRAALTA & & \\
\hline URGELL & & \\
\hline VAL D'ARAN & & \\
\hline VALLES OC & & \\
\hline VALLES OR & & \\
\hline
\end{tabular}

Fuente: Departament d'Ensenyament. Generalitat de Catalunya. Elaboración propia.

\section{DISCUSIÓN Y CONCLUSIONES}

La realidad expuesta resulta mucho más compleja de lo que se puede describir y analizar en un texto que, únicamente, pretendía ofrecer unas pinceladas sobre un proceso que incide en la sociedad catalana de principios del siglo XXI. Si bien los procesos migratorios que aportan una gran diversidad a la sociedad de acogida ya eran presentes en algunas sociedades europeas, en el caso de España y de Cataluña se tiene la impresión que no se tuvieron en cuenta experiencias anteriores (Domingo, 2014; Garreta, 2016). Mientras que la distribución de población se realiza a partir de las oportunidades laborales y las opciones personales, en el proceso de escolarización se encuentran dos parámetros básicos. Por un lado hay la obligatoriedad de la escolarización y, por otro, los recursos disponibles en el territorio. La realidad y las políticas seguidas no han evitado que determinados centros escolares se convirtieran en espacios "gueto" mientras se trabajaba para evitar la estigmatización de todo un colectivo (Bernad y Llevot, 2018; Essomba, 2014; Garreta, 2003; Llevot, Garreta, Bernad, Molet, y Domingo, 2017). La inmigración no es un fenómeno que arregle los desequilibrios territoriales, sociales o económicos existentes a su llegada pero genera nuevos parámetros a tener en cuenta. Y entre estos destacan los del ámbito educativo por 
ser un proceso social de obligado cumplimiento que afecta al conjunto del territorio. Y los procesos relacionados con la inmigración señalan una consolidación de la diversidad cultural, el aumento de la divergencia campo-ciudad y una doble realidad escolar, dependiendo del origen (Benabarre, 2018; Bernad y Llevot, 2018). Este conjunto forma un triangulo con lados desiguales donde la estructura no siempre descansa en el lado que ofrece mejor base para su funcionamiento. La composición social, su realidad cultural en el día a día, las posibilidades económicas del territorio y la estructura escolar implantada en cada comarca dibujan un panorama desigual en el conjunto de Catalunya que ha de buscar soluciones diferentes en cada caso.

En la escuela, el proceso ha generado un estímulo en buscar soluciones docentes a la realidad de cada centro (Llevot et al., 2018). La diferenciación entre los tipos de centros es solo una parte de un aspecto que puede ser analizado de manera mucho más amplia como, por ejemplo, el marco geográfico de cada centro. Y es necesario trabajar para erradicar la desigualdad en un proceso social tan básico como es el educativo (Sanuy, Bernad, y Llevot, 2017). Si la educación es uno de los medios de promoción social, de integración del individuo en la sociedad, cabe tener presente su realidad, la relación con el entorno, las necesidades sociales y las de cada individuo y cada colectivo.

\section{REFERENCIAS}

Aldomà, I. (2015). Atles de la nova ruralitat. L'actualitat del món rural. Els anys de la gran crisi a la Catalunya rural. 2008-2015. Barcelona: Fundació del Món Rural.

Bayona, J., y Gil, F. (2008). El papel de la inmigración extranjera en la expansión de las áreas urbanas. El caso de Barcelona (1998-2007). Scripta Nova, 12, 1-5.

Benabarre, R. (2018). Diversidad cultural y escuela privada: nuevas realidades y desafíos En J.J. Gázquez, M.M. Molero, M.C. Pérez-Fuentes, A. Martos, M. Simón, A.B. Barragán, y M. Sisto. (Eds.), La convivencia escolar: un acercamiento multidisciplinar (pp. 103-111). Madrid: ASUNIVEP.

Bernad, O. (2016). School and immigrant origin families. En J. Garreta-Bochaca (Ed.), Immigration into Spain: evolution and socio-educational challenges (pp.169-197). Bern (Suiza): Peter Lang.

Bernad, O., y Llevot, N. (2018). La diversidad religiosa y cultural de la escuela pública de Cataluña. En J.J. Gázquez, M.M. Molero, M.C. Pérez-Fuentes, A. Martos, M. Simón, A.B. Barragán, y M. Sisto. (Eds.), La convivencia escolar: un acercamiento multidisciplinar (pp. 119-127). Madrid: ASUNIVEP.

Bernad, O., y Llevot, N. (2016). Las relaciones familia-escuela en la formación inicial del profesorado. Opción: Revista de Ciencias Humanas y Sociales, 7, 959-976.

Bernad, O., y Llevot, N. (2018). La escuela y las familias de origen minoritario: retos a abordar en las escuelas y en las facultades de educación. En A. García (Ed.), Aportaciones de vanguardia en la investigación actual (pp. 41-55). Madrid: Editorial Tecnos.

Cabré, A. (1990). Les migracions a Catalunya, 1900-2000. En M.A. Roque (Ed.), Els moviments humans en el Mediterrani Occidental (pp. 281-289). Barcelona: ICEM. 
Cabré, A., Arango, J., Pujadas, I., Domingo, A., Oller, D., Pascual, A., y Cardellús, J. (2007). Les onades migratòries en la Catalunya contemporània. Barcelona: Fundació Lluís Carulla.

Colectivo IOÉ (1996). La educación intercultural a prueba. Hijos de inmigrantes marroquíes en la escuela. Granada: Laboratorio de Estudios Interculturales.

Convocatoria Recercaixa (2015). Proyecto: Diversidad cultural e igualdad de oportunidades en la escuela. Barcelona: Caixaforum.

Domingo, A. (2007). El segle XXI i la internacionalització de les onades migratòries. En A. Cabré, J. Arango, I. Pujadas, A. Domingo, D. Oller, A. Pascual, y J. Cardellús (Eds), Les onades migratòries en la Catalunya contemporània (pp. 49-62). Barcelona: Fundació Lluís Carulla.

Domingo, A. (2014). Catalunya al mirall de la immigració. Demografia i identitat nacional. Barcelona: Ed. L'Avenç.

Domingo, J. (2016). Immigration and territory in early 21 st-century Spain: disparities within the unity? En J. Garreta-Bochaca (Ed.), Immigration into Spain: evolution and socioeducational challenges (pp.17-27). Bern (Suiza): Peter Lang.

Domingo, J., y Bernad, O. (2017). Inmigración africana en el contexto rural de Cataluña. Revista Internacional de Estudios Migratorios, 7(1), 9-45.

Essomba, M.A. (2014). Políticas de escolarización del alumnado extranjero en el estado español. Análisis y propuestas. Revista Interuniversitària de Formación del Profesorado, 17(2), 13-27.

Garreta, J. (2003). El espejismo intercultural. La escuela de Cataluña ante la diversidad cultural. Madrid: CIDE.

Garreta, J. (2011). Atención a la diversidad cultural en Cataluña: Exclusión, segregación e interculturalidad. Revista de Educación, 355, 213-233.

Garreta, J. (2016). Associationism among African-origin immigrants in Spain. En J. GarretaBochaca (Ed.), Immigration into Spain: evolution and socio-educational challenges (pp.197-216). Bern (Suiza): Peter Lang.

Giner, S. (1997). La societat catalana. Barcelona: IDESCAT.

Institut d'Estadística de Catalunya (IDESCAT) (2017). Xifres de Catalunya. Barcelona: Generalidad de Cataluña.

Instituto Nacional de Estadística (INE) (2017). España en cifras. Madrid: INE.

Llevot, N., Bernad, O., y Benabarre, R. (2018). Diversidad cultural y religiosa: buenas prácticas en los centros de educación primaria de Cataluña. En J.J. Gázquez, M.M. Molero, M.C. Pérez-Fuentes, A. Martos, M. Simón, A.B. Barragán, y M. Sisto (Eds.), La convivencia escolar: un acercamiento multidisciplinar (pp. 127-137). Madrid: ASUNIVEP.

Llevot, N., Bernad, O., y Garreta, J. (2019). Diversidad cultural e igualdad de oportunidades en la escuela de Cataluña: retos y desafios. Barcelona: Editorial Erickson.

Llevot, N., Garreta, J., Bernad, O., Molet, C., y Domingo, J. (2017). Diversidad religiosa en las escuelas de Cataluña: de la teoría a la práctica. Ehquidad International Welfare Policies and Social Work Journal, 7, 43-80.

Llevot, N., Molet, C., Garreta, J., Bernad, O., y Domingo, J. (2017). Diversidad religiosa en los centros escolares de Cataluña: religiones y multiculturalidad. Lleida: Milenio.

Llevot, N., y Bernad, O. (2015). La participación de las familias en la escuela: factores clave. Revista de la Asociación de Sociología de la Educación (RASE), 8(1), 57-70.

Ministerio de Educación, Cultura y Deporte (2017). Estadísticas en Educación. Madrid: INE.

Palaudarias, J.M. (1998). Análisis de la política educativa en la escolarización de las minorías culturales en Catalunya. Intercultural Education, 19(6), 481-491.

Pinyol, G. (2016). Informe sobre la integració de les persones immigrades a Catalunya 2015. Secretaria d'Igualtat, Migracions i Ciutadania. Barcelona: Generalitat de Catalunya. 
Portera, A. (2008). Intercultural education in Europe: epistemological and semantic aspects. Intercultural Education, 19(6), 481-491.

Roquer, S., y Blay, J. (2008). Del éxodo rural a la inmigración extranjera. El papel de la población extranjera en la recuperación demográfica de las zonas rurales españolas (1996-2006). Scripta Nova: Revista Electrónica de Geografía y Ciencias Sociales, 12, 270.

Samper, L. (2002). Integració social dels immigrants a Lleida: noves $i$ velles migracions. Lleida: Pagès.

Sanuy, J., Bernad, O., y Llevot, N. (2017). El Programa Escuela Nueva 21 en Cataluña (España): Prácticas de Éxito para Combatir el Abandono Escolar Prematuro. Civitas Educationis. Education, Politics and Culture, 6(2), 1-5.

Silvestre, J. (2009). Las emigraciones interiores en España durante los siglos XIX y XX: una revisión bibliográfica. AGER: Revista de Estudios sobre Despoblación y Desarrollo Rural, 2, 227-248.

Recibido: 19 de junio de 2019 Recepción Modificaciones: 3 de julio de 2019 Aceptado: 17 de julio de 2019 